\title{
Chapter 17 \\ Enhancing Frontline Resilience: \\ Transborder Community-Based \\ Flood Early Warning System \\ in India and Nepal
}

\author{
Yeeshu Shukla and Bhanu Mall
}

\subsection{Introduction}

Terai ${ }^{1}$ belt in India and Nepal is considered one of the most economically backward areas due to various historical and socio-economic factors. The area is also affected by recurring floods. The ecological settings through which flooding takes place in Terai are also diverse. For years, floods have ravaged the lives of the inhabitants of this area with unrelenting regularity every alternate year and many a times for subsequent years. The current trends show frequent greater flood problems in the area than ever before thus resulting in the reversal of any gains on the developmental front (Singh 2009). The plights of the people are aggravated by regularly affected crops, health and employment due to regular floods in this region.

There have been significant flood events since 1971 leading to loss of lives and livelihoods on a regular basis. In July of 1993, Nepal experienced a devastating flood in the Terai region, which took the life of 1289 people and affected 575,000 people. In 1998, flood-affected again about half million inhabitants and caused the total loss of about 2 billion Nepal rupees (approximately \$US29 million). The Saptakoshi River floods and landslides in 2008 affected 28 districts of the country and impacted more than 300,000 people (Global Risk Identification Program). Similarly, in the Indian part of Terai, floods have affected caused considerable damage to the poor and marginalized. In 1998, 127 people lost their lives and more than 90,000 households

\footnotetext{
${ }^{1}$ Terai, also spelled Tarai, region of northern India and southern Nepal running parallel to the lower ranges of the Himalayas.
}

Y. Shukla $(\bowtie)$

Christian Aid Organization, London, UK

e-mail: yshukla@christian-aid.org

B. Mall

Poorvanchal Gramin Vikas Sansthan (PGVS) Organization, Lucknow, India

e-mail: drbhanu53@gmail.com 
were affected in the area. In the year 2008, some 170 people died and more than 2.5 million were affected with 165,000 people getting displaced (Singh 2009).

\subsubsection{Nuances of Vulnerability}

The lessons from previous interventions on early warning in the region have shown that there are some specific factors that contribute to the increased vulnerability and risk at the frontlines. These have been documented during the course of action by Christian Aid and its partners. Some of them are as follows.

Weak physical and natural resources: Weak physical and natural assets define communities vulnerable to flood. There are instances where retaining walls break, overgrazed lands subsides and dangerous mudslides, bridges collapse and crops wash away. Often communities with the weakest physical assets are the same communities that are located closest to the source of disaster-on the banks of river, for example. Since primarily poor live in such places with no means of ensuring any protection, these places often get exposed to the numerous disasters.

Degraded natural environment: Degraded lands are more susceptible to damage, during natural events. Healthy, biodiverse forests or river banks/coasts with vegetation can absorb water to some extent. Land abundant grasses and vegetation also soak up excess water. Overgrazing and deforestation have led to destructive landslides, and crops unprotected by bunds and other conservation measures wash away.

Inadequate access to support structures: Communities located in the most fragile environments are the same communities that lack the social and political assets needed to attract important government resources-better roads, strong bridges, sturdy tanks and shelters, or relief supplies. Poor access to government and nongovernment support impedes a community's ability to withstand disaster.

Lack of disaster preparedness: Communities in flood-prone areas already have coping strategies to address flood, but they are often insufficient in the face of major flood. Good planning (and ensuing implementation) is, for vulnerable people, the best defence against disaster. This is especially true for marginalized communities living in vulnerable locations_-sick, handicapped or elderly people, small children, expectant mothers and resource-poor families who have been pushed to dangerous ground or who lack the means to escape or survive.

Inadequate mechanism for timely information flow: Most of the communities within flood-prone areas are devoid of any form or reliable information which can be used to prepare for upcoming disasters. Often they come to know about floods when it strikes their habitat and they are affected by it, by then it is too late to respond. It is not that there is lack of information about the onset of disaster. However, the issue is of its dissemination to communities vulnerable to it. Based on field assessment, there is clear evidence of information sharing between authorities on Nepal (Department of Hydro-Meteorology) and India (irrigation department); most of these information remain within the administrative setup and seldom reaches the 
desired recipient. Therefore, it is desirable to have early warning mechanism which is based in community and can be managed locally without much technology. It is vital that sustainability is imbibed into the core of its principle.

\subsubsection{Why Disaster Risk Reduction?}

The above lessons have been derived and documented by working with the communities in the region which brings out a clear need for a robust disaster risk reduction mechanism having a potential to minimize disaster risk for the communities living at the frontlines. The Sendai Framework of Disaster Risk Reduction (SFDRR) ${ }^{2}$ promotes such a people-centred approach to early warning as one of the priority areas for communities to avoid risks. The objective of people-centred early warning systems is to empower individuals and communities threatened by hazards to act in sufficient time and in an appropriate manner so as to reduce the possibility of personal injury, loss of life, damage to property and the environment and loss of livelihoods

The underpinning assumption is that this requires strong community participation on the ground and enabling environment for greater cooperation across various stakeholders including the government authorities in India and Nepal across levels on knowledge and information sharing. As it is known that the resilience agenda could also move to become a more integral part of ongoing local development processes, so it would be appropriate to look into the above processes and policies in the mainstream development planning.

\subsection{The Initiative}

In order to address some of the above-mentioned concerns, Christian Aid with its local partner Poorvanchal Gramin Vikas Sansthan (PGVS) initiated a pilot on flood early warning systems in the Terai region of India and Nepal on the Karnali (Nepal)-Ghaghra (India) river basin. The initiative is provided technical assistance by Practical Action and financial assistance from Cord Aid. This involved accessing data available with relevant government departments, dissemination and communication and collaborative arrangements with the private sector for IT-based solutions. The project in the initial pilot phase has achieved some tangible results in terms of institutionalizing the effective community preparedness mechanism utilizing and demystifying the technical knowledge available from both Nepal and India. The project focuses on following broad objectives:

\footnotetext{
${ }^{2}$ The Sendai Framework for Disaster Risk Reduction 2015-2030 (Sendai Framework) is the first major agreement of the post-2015 development agenda, with seven targets and four priorities for action.
} 
1. To establish transborder community-based early warning system using Information and Community Technology along the Karnali River in Nepal and Ghaghra River in India with the focus on strengthening frontline resilience.

2. To build the capacity of local community-based institutions on effective flood preparedness with clear linkages between upstream and downstream.

3. To develop formal and informal communication channels to access early information on water levels from upstream in Nepal.

4. To strongly advocate for having effective community-based Early Warning System (EWS) across flood-prone Terai in India and Nepal (Fig. 17.1).

\subsubsection{Information and Communication Technology (ICT) for Flood Resilience}

The EWS system being implemented in the Terai region of India and Nepal offers huge potential for bringing technology and community action together by demystifying the concept of technology-centred approaches involving people who are expected to be affected by the disasters. The system involves following key elements and processes.

\subsubsection{Monitoring and Warning}

The system begins with facilitating capture of information for monitoring and dissemination of warning with the incorporation of ICT solutions suited to emergency situations. The water levels are monitored in the upstream at Chisapani in Nepal and cross checked with the information being generated by Department of HydroMeteorology, Government of Nepal. The same information is channelized to the India side. Christian Aid partner-PGVS with the help of Gram Panchayat ${ }^{3}$ (local elected body) and community groups have established electronic display machine in district Bahraich and Gonda in India. The display machine shows water level in Karnali River at Chisapani in Nepal. The digital river monitoring system receives the readings directly from Department of Hydro-Meteorology (DHM) through Internet, and it reflects information in real time. This provides a fair idea of the lead time that the communities in the downstream have depending on the water levels.

The system is also equipped with alert alarm system which gets activated based on the water levels in Nepal. The alert is based on the threshold limits based on past experiences of water levels and floods in the region. The recorded thresholds are shown below.

\footnotetext{
${ }^{3}$ A Gram Panchayat is the cornerstone of a local self-government organization in India of the Panchayati raj system at the village or small town level, and has a Sarpanch as its elected head.
} 
17 Enhancing Frontline Resilience: Transborder Community-Based ...
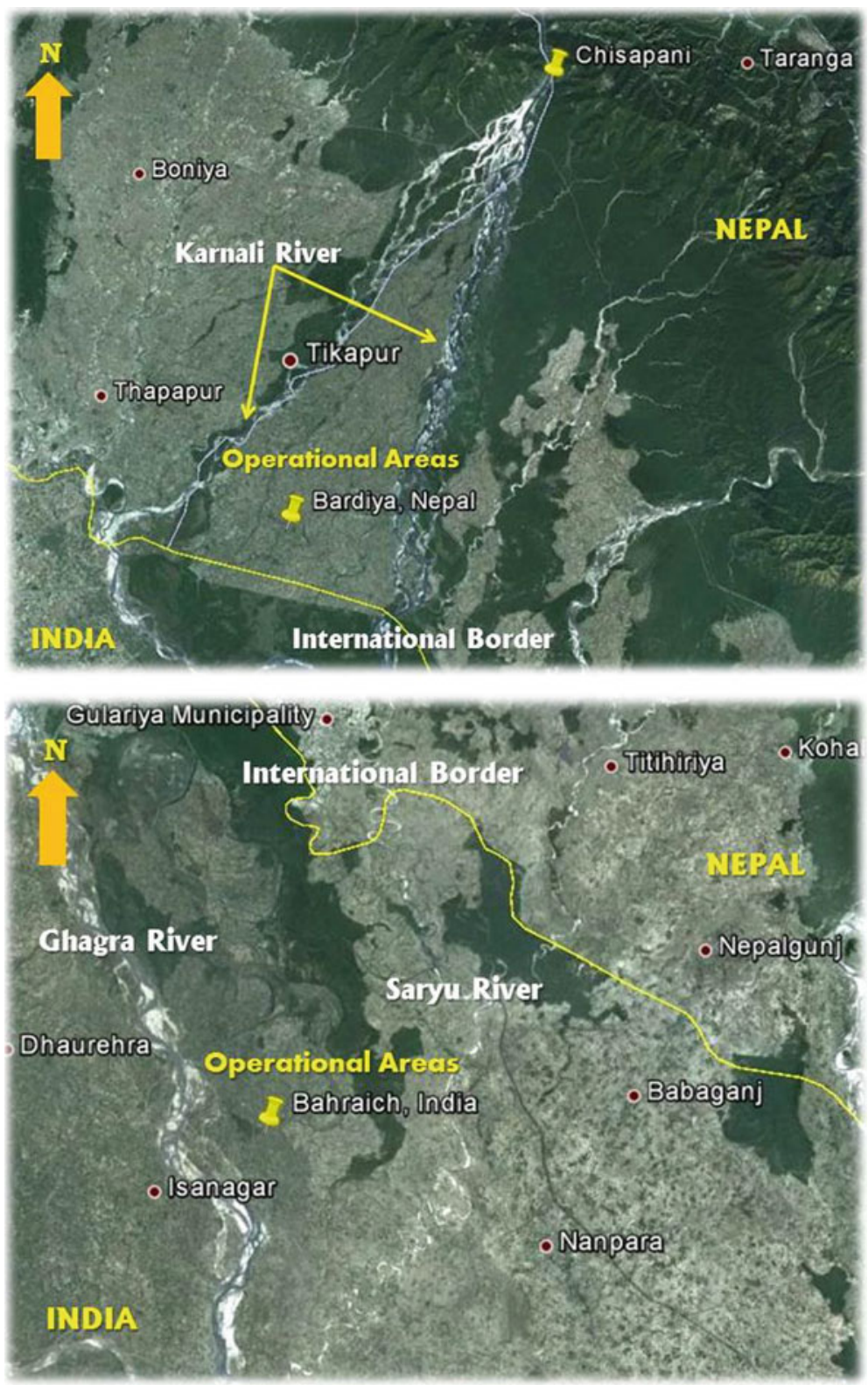

Fig. 17.1 Operational areas in India and Nepal. Source Google Earth

Figure 17.2 provides an example of water levels in Nepal and India and the respective alert and warning levels. The data shown in the alert is not taken from Mean Sea Level (MSL) but the level of water recorded at the points where rain 

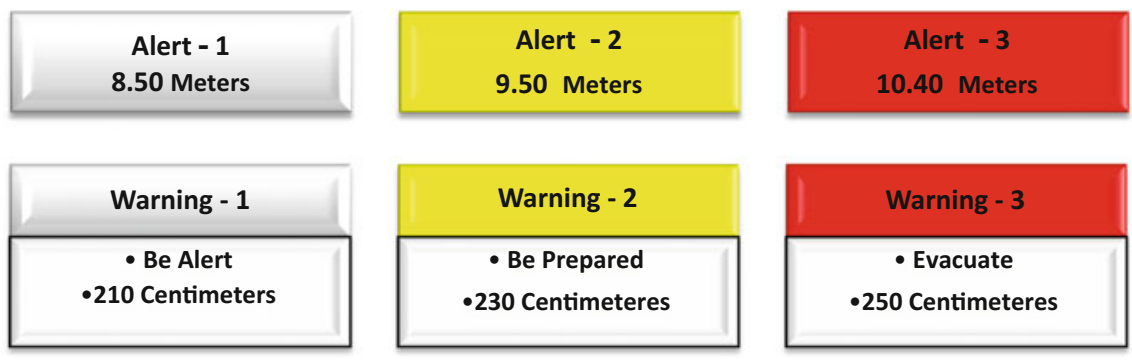

Fig. 17.2 Example of warning and alert levels based on the thresholds recorded from the past experiences. Source PGVS

gauges have been established in Nepal and India. The alert levels are fairly specific to a particular community and warnings are issued for a particular community based on the water levels compared to pre-monsoon levels. Hence, the system takes into account a locale-specific vulnerability, and exposure to rising waters and provides a context-specific warning.

\subsubsection{Generating Data from the Frontlines}

The project has been instrumental in the installation of river gauges at strategic locations close to the villages which get affected due to the floods in the region. The water level is periodically monitored at these locations along with the data generated by DHM. The information is then corroborated for issue of alerts from the district hub. It is important to mention that this information is generated by the communities trained as task forces under the initiative from the project villages.

\subsubsection{Dissemination of Alerts and Warnings}

In addition to the electronic display boards in the communities which could lose connectivity during floods, information is shared with voice and text messages. The mobile numbers of key personnel both in the communities and district and state level functionaries are registered for dissemination of information.

The contacts are arranged in groups based on the project area and can be subdivided as well. This gives a quick access during emergencies. The information is directly sent to all the mobiles registered in the group and information can be given in local language as well (Hindi). This is handled by authorized personnel of communication department of the PGVS or anyone assigned by the authority. Similarly, voice messages are sent with demystified information to the people expected to be affected by the rising waters. 


\subsubsection{Feedback Mechanism}

The feedback promoted by the system uses ICT mechanism of helpline number. The service is known as super receptionist service and is based on Interactive Voice Service (IVR). The number is Indian and local charges apply which is based on network. During emergency situations, the lines are opened which promotes twoway communication and encourages people to feedback into the system.

Super Receptionist IVR combines technology with the available tools. The listing and grouping as an outgoing service is also present along with $24 \mathrm{~h}$ incoming service. ICT technology improvises inductive use of telecom services and appropriate for the emergency response. As far as monitoring goes, no external resource needs to be adapted as internal mechanism of recording calls and download the report facility is available (PGVS 2016) (Fig. 17.3).

\subsection{System in a Real World Situation (Case from Village Somai Gauri)}

\subsubsection{Background}

Village Somai Gauri is situated in Mihinpurwa Block in district Bahraich is around 97 $\mathrm{km}$ from district administrative office. The Palihapurawa hamlet situated under this Gram Panchayat is situated in north-east direction. The Log and Lat of this village is $275837 \mathrm{~N}$ and 811534 East. The total population of this village is 765 (Male 390 and Female 375) with most of them belonging to backward caste. The Gram Panchayat is located very close to the Ghaghra River that originates from Nepal and popularly known as Karnali within Nepal. Floods are a regular phenomenon in this Gram Panchayat which causes widespread devastation to the lives and livelihoods.

The river is constantly changing course and the distance of the River from village, which used to $6 \mathrm{~km}$ some $6-8$ years ago, now reduced to less than $1 \mathrm{~km}$. Growing paddy crop is impossible in these areas due to the heavy flood. Only sugarcane and corn crops are main agricultural products of these areas which also get affected at times. The early warning system was initiated in the village on 1 April 2012 for enhancing the flood resilience of the communities through better coordination and linkages between upstream and downstream communities.

\subsubsection{Local Action by People}

The initiative began with engaging people in their self-analysis of existing vulnerability and capacity. A systematic approach called Participatory Vulnerability and Capacity Assessment (PVCA) were carried out and Task forces at village level and Village Disaster Management Committee at Gram Panchayat level were formed and 


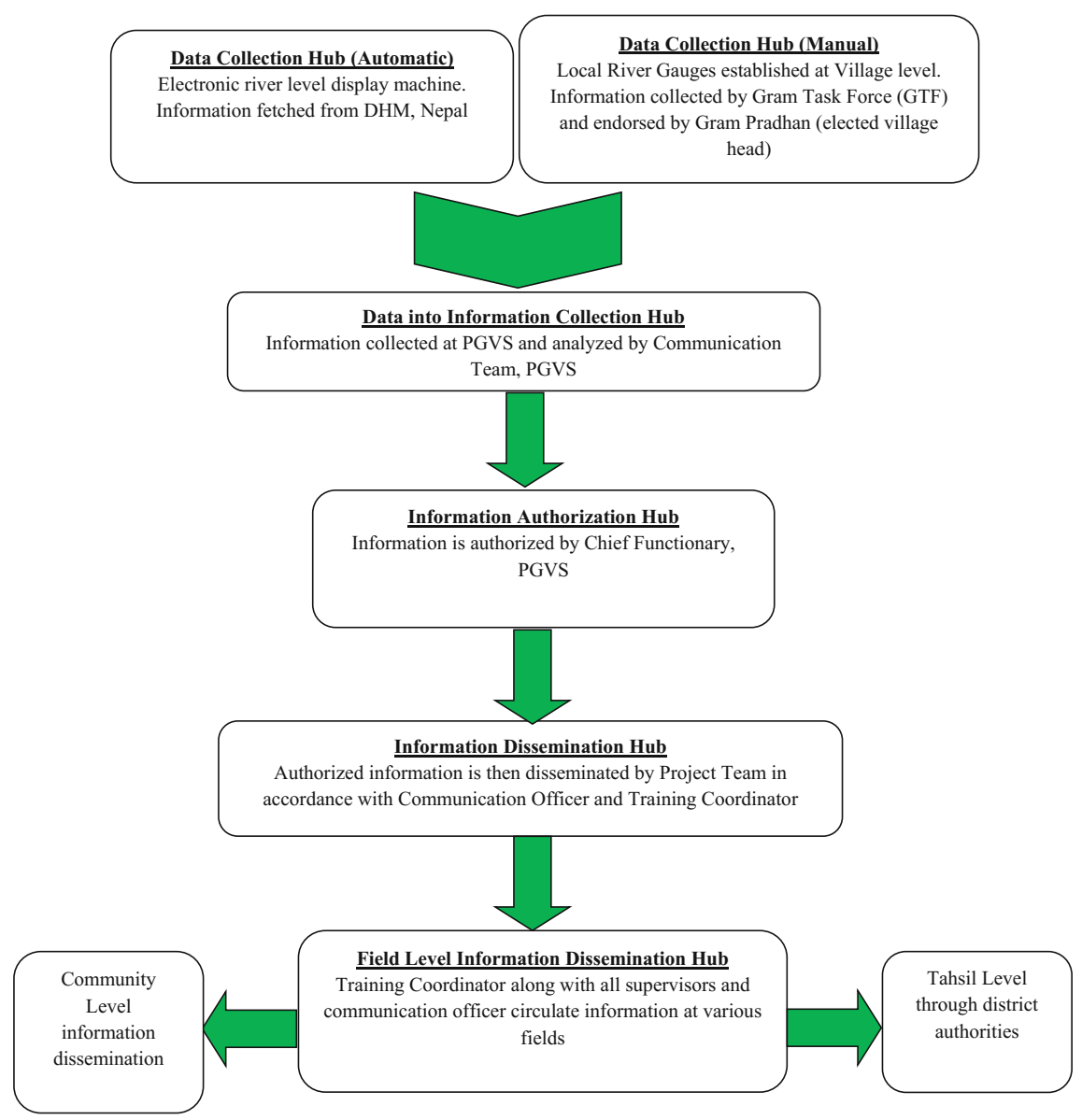

Fig. 17.3 Flow chart of the transborder ICT mechanism

linked to the established community-based early warning centres under the leadership of Gram Panchayat (local elected body). The river monitoring display board has been established in Palihapurawa, district Bahraich and Pure Baloo, district Gonda in coordination of Department of Hydro-Meteorology, Nepal, and River gauges are also established in villages by Gram Task Force (GTF) under the supervision of Gram Panchayat. The Gram Panchayat and GTF have taken responsibility for maintenance and safety of the equipment.

The GTF has divided into three groups like Early Warning and Communication Group, Search and Rescue Group and First Aid and Shelter Management Group, consisting of 15 members of Gram Task force in each village. Gram Task force has been trained on search and rescue, first aid and shelter management. The Gram Task force has all the maps which were developed during PVCA exercise including important contact numbers related to Disaster and Development Department, information on 
engineers associated with local dams and their contact number, etc., the life-saving equipment like life jackets, floating rings, ropes with carabineers, and siren's has been kept in village community-based early warning centre. The Gram Task forces have been involved in conducting mock drill in their village before the monsoons.

\subsubsection{Floods of 2013}

In the year 2013 when the area faced severe floods, villagers from Somai Gauri were able to evacuate in time with their personal belongings to safer places. They utilized the information generated from the EWS and the training that they received from the project team.

When the water levels started rising, Early Warning and Coordination Group member discussed with all Gram Task forces including village head about the changing river trends and started taking data from river monitoring system four times in a day (6 AM, 10 AM, 2 PM and 6 PM each day) and shared the status with the president of the Gram Task force. The same was also communicated with the village head, PGVS team and sub-divisional office, Nanpara through mobile phone every day. PGVS early warning team then shared this information through text message and voice messages with multiple stakeholders. The Gram Pradhan (village leader) puts his signature on river monitoring register at 6 PM every day in the evening. The task force based on the warnings and rising level of water placed a one corner white flag at early warning centre and peals the siren for $30 \mathrm{~s}$ as alert situation to the villages.

The Gram Task Force member simultaneously disseminated flood information to villagers in the nearby villages by the existing communication channel. After this first alert, people started organizing their domestic vital materials, important documents, livestocks, ornaments and food materials.

The water level of Ghaghra River at Chisapani, Nepal crossed its warning level and reached $10.24 \mathrm{~m}$ on 17 June 2013 at $6 \mathrm{PM}$ evening and reached $1.80 \mathrm{~m}$ on the same day reflected in the village River gauge located close to the village. A rapid call to all GTF members was given and Early Warning and Coordination Group was activated. Now village head asked GTF members to place the two corner white flag and peal the siren two times for $30 \mathrm{~s}$. The GTF members disseminated the flood information to the village heads of other nearby villages and communities started prepositioning of food and other essential. The flood waters entered agriculture land on 18 June 2013 at 5 am, and slowly water entered the village. Mr. Ram Pal took quick action and informed village head about the situation through mobile and village head quickly asked the task force to place a three corner white flag at EWS centre and peal the siren continuously in the village. 


\subsubsection{Benefits}

By these efforts and quick responses of the Gram Pradhan and GTF members, communities could manage to evacuate safely from the village and reached Jalimnagar Bridge with all required materials and established their shelter during flood period. The flood water stayed in village for 2 days at the height of about 3-4 ft and started reducing from $4 \mathrm{PM}$ on 20 June 2013. There was no loss of lives due to the advance information and improved coordination among community and local institutions.

\subsection{Conclusion}

Information on climate change is building a new perception of disasters as of our own making. The increase in floods, storms, droughts and other hazards expected to arise from the accumulation of greenhouse gases in the atmosphere as a result of industrialization and deforestation is clearly not natural (UNISDR 2008). Most of the literature and scientific consensus now confirms that no matter whatever we do to reduce the greenhouse gas emissions, the human-induced changes in climate is inevitable. So this brings forth the need for reduction in emissions and most importantly being prepared for changes holds the key.

Effective preparedness and early communication to these growing changes will require strategies, institutions and structures that are robust under uncertainty. Moreover, as communities are directly getting affected, their own coping mechanisms, capacities and willingness to adapt newer technologies are of extreme relevance and need to be studied in detail. The traditional knowledge used as coping mechanisms as also the new mechanisms developed over the years provide greater resilience to the communities in times of growing climate threats. At the same time, it is equally important to understand the existing policy regime in the context of lifeline communication systems like early warning mechanism in transboundary river systems with a dynamic fluvial landscape and other overriding geopolitical concerns.

The robust EWS systems also present an opportunity to look into the feasibility of ICT technology having strong human/community linkages for scaling up in other regions with similar vulnerability, hazards and risks with a focus on transborder water resources management for disaster risk reduction in times of changing climate. However, there are several challenges in implementing EWS systems in a transborder context and some of the actions required to strengthen the EWS systems could be as follows. 


\subsubsection{Generating Buy in for EWS}

To scale up the EWS in the multi-hazard zones, it is fairly important to have a favourable environment which includes having a clear buy in with the government systems at various levels, non-government organizations and communities at the frontlines. This could be done with piloting such approaches and documenting the evidence of the benefits of the approach for at-risk communities. The evidence generated needs to be effectively communicated to the government and other actors for taking this forward and making it a priority action for minimizing the loss of lives and livelihoods.

\subsubsection{Accelerating Regional Information Sharing}

One of the major bottlenecks in streamlining and implementing such systems is related to lack of effective regional information sharing mechanism between respective governments. India and Nepal have a Joint Committee on Water Resources (JCWR) and the last meeting of the committee took place in January 2013. This is a good mechanism for streamlining regional cooperation. However, the frequency of the exchanges needs to be enhanced and the discussion needs to take specific hazards and vulnerabilities that the region faces due to the floods. Similarly, civil society initiatives on both sides need to be explored involving people from all walks of life. Christian Aid and its partner are trying to create such a mechanism between the civil society groups of both the countries.

\subsubsection{Participation, Social Cohesion and Active Involvement}

Participation and active involvement of the at-risk communities is the backbone of the high user interface ICT systems. Another important aspect is related to co-creating with potential participants who would help innovate and troubleshoot bottlenecks on a regular basis. This could also lead to development of multiple co-creation teams having insights on specific physical, social and economic context.

\subsubsection{Capacity Building as Ongoing Activity}

Actions need to be substantiated with continual capacity building inputs. Often, it is seen that capacity building is seen as one-time activity. The content should be based on the local knowledge base in line with the technical infrastructure. Efforts should be focused on simplifying the use of technical aspects of the system which 
could be used by a large number of population. This is critical for scaling up the innovation to other areas and increase uptake. Gaps need to be identified during the implementation phase and specific modules need to be developed to address these gaps.

Acknowledgements We would like to offer our sincere thanks to Mr. Krishna Tripathi and Mr. Shivanshish Snha (both PGVS staff) for their inputs on the paper.

\section{References}

24-25 January 2013, Kathmandu, Minutes of the Seventh Meeting of Nepal-India Joint Committee on Water Resources (JCWR).

Ahmed, S., \& Dixit, A. (2007). Working with the winds of change: toward strategies for responding to the risks associated with climate change and other hazards, IDRC and DFID

Asia-Pacific Input Document for the Post-2015 Framework for Disaster Risk Reduction (HFA2), 2014

Global Risk Identification Programme, Historical Disaster Profile of Nepal (based on NSET disaster observatory database).

Hyogo Framework of Action-2005-15

IUCN, \& IISD. (2008). Livelihoods and climate change: combining disaster risk reduction, natural resource management and climate change adaptation in a new approach to the reduction of vulnerability and poverty. International Institute for Sustainable Development

Mercy corps and Practical Action. (2010). Establishing community based early warning system, Practioner's handbook.

Sendai Framework of Disaster Risk Reduction 2015-30

Singh, G. (2009). The natural disasters in the Eastern Uttar Pradesh, India

Summary report by IPCC, 2007, 2014

United Nations International Strategy for Disaster Reduction Secretariat, Geneva, Links between Disaster Risk Reduction, Development and Climate Change, 2008

Venton, P. (lead author), \& La Trobe, S. (2008, July). Linking climate change adaptation and disaster risk reduction, Tearfund.

Open Access This chapter is licensed under the terms of the Creative Commons Attribution 4.0 International License (http://creativecommons.org/licenses/by/4.0/), which permits use, sharing, adaptation, distribution and reproduction in any medium or format, as long as you give appropriate credit to the original author(s) and the source, provide a link to the Creative Commons license and indicate if changes were made.

The images or other third party material in this chapter are included in the chapter's Creative Commons license, unless indicated otherwise in a credit line to the material. If material is not included in the chapter's Creative Commons license and your intended use is not permitted by statutory regulation or exceeds the permitted use, you will need to obtain permission directly from the copyright holder. 